\title{
Daily zinc supplements reduced the incidence and severity of acute lower respiratory infections in children in India
}

Sazawal S, Black RE, Jalla S, et al. Zinc supplementation reduces the incidence of acute lower respiratory infections in infants and preschool children: a double-blind, controlled trial. Pediatrics 1998 Jul;102:1-5.

\section{Question}

Can zinc supplementation reduce the incidence and severity of acute lower respiratory infections in infants and preschool children in India?

\section{Design}

6 month randomised, double blind, placebo controlled trial.

\section{Setting}

Community based clinic in a city in India.

\section{Patients}

609 children who were $6-35$ months of age (mean age 19 mo, $52 \%$ boys), had attended a community based clinic for diarrhoea, and had recovered from the initial diarrhoeal episode. Follow up was $99 \%$.

\section{Intervention}

Children were allocated to zinc gluconate, $10 \mathrm{mg}(\mathrm{n}=298)$, or placebo $(\mathrm{n}=311)$ given daily in $5 \mathrm{ml}$ of liquid supplement containing vitamins A (800 U), B1 (0.6 mg), B2 (0.5 mg), B6 (0.5 mg), D3 (100 U), and E (3 mg) and niacinamide $(10 \mathrm{mg})$. Duration of treatment was 6 months. Children who had diarrhoea received $10 \mathrm{ml}$ of the supplement while they were ill.

\section{Main outcome measures}

Number of episodes of and days with acute lower respiratory infection, which was defined as having a cough and (1) raised respiratory rate or $(2)$ temperature $\geqslant 101^{\circ} \mathrm{F}\left(38.3^{\circ} \mathrm{C}\right)$ or the presence of lower chest indrawing.

\section{Main results}

24 and 44 episodes of acute lower respiratory infection occurred in the zinc ( 0.19 episodes/child/y) and placebo ( 0.35 episodes/ child/y) groups, respectively. Children in the zinc and placebo groups had 155 and 264 days, respectively with acute lower respiratory infections. Compared with placebo, zinc led to a reduction in the incidence of $(\mathrm{p}=0.018)$ and number of days with $(\mathrm{p}<0.001)$ acute lower respiratory infections. Because a child could have $\geqslant 2$ episodes related to one another over the 6 month period, a statistical adjustment was made. After this adjustment, similar results were obtained for incidence $(p=0.02)$ but not for the number of days with acute lower respiratory infections $(\mathrm{p}=0.054)$ (table).

\section{Conclusion}

A daily dietary zinc supplement led to a decrease in the incidence and severity of acute lower respiratory infections in infants and preschool children in India.

Zinc supplements $v$ placebo in infants and preschool children in India

\begin{tabular}{|c|c|c|}
\hline Outcomes at 6 months & $\begin{array}{l}\text { Unadjusted odds ratio } \\
(95 \% \mathrm{CI})\end{array}$ & Adjusted odds ratio ${ }^{(C I)}$ \\
\hline Incidence of ALRI* & $0.55(0.33$ to 0.91$)$ & $0.55(0.33$ to 0.90$)$ \\
\hline $\begin{array}{l}\text { Number of days with } \\
\text { ALRI }\end{array}$ & $0.60(0.49$ to 0.73$)$ & $0.59(0.35$ to 1.00$) \neq$ \\
\hline
\end{tabular}

$* \mathrm{ALRI}=$ acute lower respiratory infection.

$\dagger$ Adjusted for $\geqslant 2$ episodes in the same child.

†Not significant.

Sources of funding: World Health Organisation Diarrheal Disease Control Program; Thrasher Research Fund; Johns Hopkins Family Health and Child Survival Cooperative Agreement; US Agency for International Development; National Institutes of Health

For correspondence: Dr R E Black, Department of International Health, Johns Hopkins School of Public Health, Room 5039,615 N Wolfe Street, Baltimore, MD 21205, USA. Fax +14109557159.

\section{Commentary}

The studies by Sazawal et al and Macknin $e t$ al provide different conclusions on zinc treatment for children with lower respiratory infection or the common cold. These studies are preceded by at least 10 randomised controlled trials of zinc lozenges for adult patients with colds ( 5 had positive results and 5 had negative results) and at least 2 reviews of some of the same trials. ${ }^{12}$

The study by Sazawal et al could be considered a landmark because it showed that a simple measure such as zinc supplementation reduced respiratory morbidity in preschool children in India. Although valid, some would argue about the practicality of giving treatment because preparations were given by field workers. The study sample represents the poorest socioeconomic stratum of urban society, and it is therefore difficult to extrapolate these findings to the general population.

The study by Macknin et al was well executed. However, no beneficial effects of zinc lozenges on the common cold among schoolchildren were found. This study had several limitations including possible unreliable reporting from students and patient selection from suburban school districts. The authors are laud- ably forthcoming about the potential biases of this study, and they allude to improvements in design for future trials within the field.

With no consensus between these 2 studies and conflicting results in previous studies, the factors that might explain such diverse findings merit consideration. These might include timing of administration (prophylactically compared with at symptom onset), differing formulations and dosages, baseline nutritional status and zinc levels of study participants, and other socioeconomic factors. Zinc (continued on page 13) 


\title{
Zinc gluconate lozenges were not effective for treating the common cold in children and adolescents
}

\author{
Macknin ML, Piedmonte M, Calendine G, et al. Zinc gluconate lozenges for treating the common cold in children. A randomized \\ controlled trial.JAMA 1998 Jun 24;279:1962-7.
}

\section{Question}

Are zinc gluconate lozenges effective for reducing clinical symptoms in children and adolescents with the common cold?

\section{Design}

21 day randomised, double blind, placebo controlled trial.

\section{Setting}

2 suburban school districts in Cleveland, Ohio, USA.

\section{Patients}

249 students (median age 13 y, $52 \%$ girls, $92 \%$ white) who had $\geqslant 2$ of the following symptoms: cough, headache, hoarseness, muscle ache, nasal congestion, nasal drainage, scratchy throat, sore throat, or sneezing. Exclusion criteria were oral temperature $>37.7^{\circ} \mathrm{C}$, previous use of zinc gluconate lozenges, pregnancy, known adverse reaction to zinc, known immune deficiency, other acute illness, or cold symptoms lasting $>24$ hours. Follow up was $96 \%$.

\section{Intervention}

$3.75 \mathrm{~g}$, hard candy lozenges that were composed of sucrose, corn syrup, aminoacetic acid, cherry flavouring oils, and either zinc gluconate trichydrate, $10 \mathrm{mg}$ or placebo (calcium lactate pentahydrate). Students were allocated to zinc lozenges (Cold-Eeze, Quigley Corporation, Doylestown, PA, USA) $(\mathrm{n}=125)$ or placebo lozenges $(\mathrm{n}=124)$ until their cold symptoms had been resolved for 6 hours. All students took 3 lozenges each school day. Students in grades 1-6 took 2 lozenges each school night and 5 each day on the weekend; those in grades 7-12 took 3 lozenges each school night and 6 each day on the weekend.

\section{Main outcome measures}

Time to resolution of cold symptoms. Secondary outcome measures were adverse events, success of blinding, medication use, and treatment adherence.

\begin{abstract}
Main results
The median time to resolution of all cold symptoms did not differ between groups ( $9 \mathrm{~d}$ in both groups); this lack of effect remained when elementary school students and junior and high school students were analysed separately. No differences in the time to resolution of symptoms existed when each of the cold symptoms was analysed separately. The study had $>98 \%$ power to detect a $42 \%$ difference in the median time to resolution of all cold symptoms and $\geqslant 80 \%$ power to detect a $42 \%$ difference when elementary school students and junior and senior high students were analysed separately. The overall incidence of adverse events did not differ between groups, but more students in the zinc group than in the placebo group reported a bad taste $(60 \%$ v $38 \%, \mathrm{p}=0.001)$; nausea $(29 \%$ v $16 \%, \mathrm{p}=0.01)$; mouth, tongue, or throat discomfort or irritation (37\% v 24\%, $\mathrm{p}=0.03)$; and diarrhoea $(11 \% v 4 \%, \mathrm{p}=0.05)$. More patients in the zinc group than in the placebo group correctly guessed which treatment they were receiving on day $2(46 \% v 24 \%$, $\mathrm{p}=0.001)$ and at the end of the study $(56 \% \quad v \quad 42 \%$, $\mathrm{p}=0.02$ ). The median percentage of prescribed lozenges taken was $83 \%$ for both groups. The duration of cold symptoms was not associated with treatment adherence or with the dose of zinc given per body surface area each day.
\end{abstract}

\section{Conclusion}

Zinc gluconate lozenges were not effective for reducing symptoms of the common cold in children and adolescents.

Source of funding: Quigley Corporation, USA.

For correspondence: $\operatorname{Dr}$ M L Macknin, Department of Pediatrics and Adolescent Medicine, A120, Cleveland Clinic Foundation, Cleveland, OH 44195, USA. Fax +12164453523. (commentary continued from page 12) appears to have a role in child health in developing countries, as Sazawal et al have shown. Studies such as these open the field to more studies of children in different geographic locations, with more varied socioeconomic and, possibly, dietary risk factors.

The results of both studies are relevant not only to paediatric nurses and public health nurses but also to health visitors, general practice nurses, and specialist community nurses involved in giving parental guidance. Evidence to support recommendations for zinc lozenges for the common cold and acute lower respiratory infection is lacking. Although many alternative treatments for acute respiratory infections exist, ${ }^{3}$ none has the evidence to warrant recommendation. More work needs to be done on zinc treatment before it can be recommended.

Both studies emphasise the need for practitioners to present information on zinc to parents in an even handed manner. As with any proposed intervention, nurses need to be able to present a critical appraisal of new developments and a balanced picture of the risks and benefits of potential treatments.
Nicola J Baker, RGN, RM, BSc Primary Care Development/ Specialist Practitioner Nottingham Community Trust Nottingham, UK

1 Eby GA. Zinc ion availability-the determinant of efficacy in zinc lozenge treatment of common colds. I Antimicrob Chemother common colds.

2 Godfrey JC, Godfrey NJ, Novick SG. Zinc for treating the common cold: review of all treating the common cold: review of all
clinical trials since 1984. Altern Ther Health Med 1996;2:63-72.

3 Turow V. Alternative therapy for colds [letter]. Pediatrics 1997;100:274-5. 